\title{
Impact of Student Participation in Webinars on Increasing Motivation to Learn
}

\author{
Ekaterina Viktorovna Mussaui-Ulyanishcheva, ${ }^{1, *}$, Elena Viktorovna Zakharova ${ }^{2}$ \\ ${ }^{1}$ Department of Foreign Languages, Faculty of Humanities and Social Sciences, Peoples' Friendship University of Russia (RUDN \\ University), Russia \\ ${ }^{2}$ Department of Foreign Languages, Faculty of Philology, Peoples' Friendship University of Russia (RUDN University), Russia
}

Received August 24, 2020; Revised October 22, 2020; Accepted November 1, 2020

\section{Cite This Paper in the following Citation Styles}

(a): [1] Ekaterina Viktorovna Mussaui-Ulyanishcheva, Elena Viktorovna Zakharova , "Impact of Student Participation in Webinars on Increasing Motivation to Learn," Universal Journal of Educational Research, Vol. 8, No. 12, pp. 6953 6959, 2020. DOI: 10.13189/ujer.2020.081262.

(b): Ekaterina Viktorovna Mussaui-Ulyanishcheva, Elena Viktorovna Zakharova (2020). Impact of Student Participation in Webinars on Increasing Motivation to Learn. Universal Journal of Educational Research, 8(12), 6953 - 6959. DOI: 10.13189/ujer.2020.081262.

Copyright@2020 by authors, all rights reserved. Authors agree that this article remains permanently open access under the terms of the Creative Commons Attribution License 4.0 International License

\begin{abstract}
Recently, the attention of researchers from various branches of knowledge has been focused on the phenomenon of electronic conferences, including webinars, which allow the exchange of information and knowledge between participants in the educational process, as well as encourage them to cooperate actively. The purpose of the study is to reveal the influence of webinars as one of the main forms of distance learning in social and psychological disciplines on increasing the motivation for learning. The study used the following research methods: theoretical analysis of psychological, pedagogical, methodological and educational literature and educational standards and programs for professional and practical training of students of humanitarian specialties to generalize theoretical issues of the essence, functions and features of the use of webinars to increase the motivational component of education; empirical - observation, interviews, questionnaires, analysis of the activities of teachers and students; mathematical - statistical methods of data processing to analyze the impact and trends of changes in student motivation in the case of using webinars. To identify the educational motives of students of humanitarian specialties, the study used a self-diagnosis method. Based on the questioning of students, the educational motives of students of humanitarian specialties have been clarified and the influence of webinars on increasing the motivation for learning has been determined. The data obtained indicated a positive effect of webinars on the change in the importance of the motives "gaining
\end{abstract}

knowledge" and "mastering a profession" upward after webinars.

Keywords Webinar, Distance Learning, Motive, Motivation, Opportunities for Distance Learning, Limitations of Distance Learning

\section{Introduction}

Continuous development and improvement of ICT tools determine the introduction of sufficient changes in the information and educational environment of universities, in particular, concerning the forms of organization of the educational process [1-3]. Modern distance learning, based on the use of Internet technologies, aims to create, manage, select educational content and storing information about students and monitor their progress, as well as constant communication, is becoming the traditional basis of the educational process [4-6].

One of the main forms of distance learning is webinars. Although at the moment this type is promising and effective, its use in education has not yet received proper distribution [7-9]. Therefore, the issues of using webinars directly in the educational process and its impact on the effectiveness of learning are relevant.

Today, there are different ideas about webinars, and numerous interpretations of the concept in question have 
been given. In addition, attempts have been made to analyze the features of the newest way of exchanging educational information in the context of the rapid process of general informatization of education, the growth of the diversity of ICT and the rapid introduction of innovative and pedagogical technologies.

As a form of learning, the webinar has been functioning already at the end of the 1990s. At the same time, the first systematic developments on the topic began to appear recently. Let us present only a few definitions of the phenomenon under consideration. Thus, in the study by $\mathrm{S}$. Hrastinski [10], this technology is interpreted as an online analogue of traditional forms of education - lectures and seminars. C.L. Johnson and J.B.Schumacher [11] believe that a webinar is an interactive lesson organized using the Internet and special software.

D. Burton and T. Kitchen [12] consider a webinar a kind of educational technology that provides interactive learning events in a synchronous mode and tools for remote collaboration of participants. According to the study [13], a webinar is a new format of learning, which offers real-time classes based on modern communication technologies that ensure the transmission of audiovisual information.

S. Cornelius [14] believes that a webinar is a form of interactive learning sessions with listeners via the Internet using special software. R. Ferguson [15] calls a webinar a virtual seminar organized using Internet technologies and representing a technology of educational cooperation, that is, group interaction of subjects of the educational process.

To summarize, the above definitions convey the idea of conducting online webinars with the transmission of audiovisual information. A prerequisite for such classes is the connection between the teacher and students. It is appropriate to interpret the technology under consideration as an interactive network form of organizing a learning session, a prerequisite for which is the areas of information and software resources. It is a lecture (seminar) on the Internet information network online.

Today, researchers $[16,17]$ distinguish the following types of webinars: educational, organizational, webinars to support research, information and presentation, consulting, webinars-interviews, etc. Each of these types has its own characteristics, as well as unconditional benefits for the educational process. For example, a well-organized information and presentation webinar will be an excellent addition to the traditional practice of presenting factual information in the form of lectures, seminars or practical exercises.

W.P. McKinney [18] points out that a remarkable feature of webinars is a rational combination of visual and audiovisual communication, verbal and nonverbal information, where the recipients are not only passive observers, but also active participants in creative educational action. During online communication, each student can ask questions to the teacher (moderator). Online polling is skillfully combined with visualized discussion, discussion, file sharing, etc. The opportunity to join the discussion creates motivation for further learning and emotional uplift that contributes to the rapid assimilation and dissemination of relevant information and optimizes well-coordinated communication between the teacher and students.

According to R. Polanco-Bueno [19], a prerequisite for a successful webinar is knowledge of the specifics of organizing online seminars and the ability to use advanced web technologies. It is necessary to take into account how a person, in particular a teacher and a student, functions in the "person - technical learning aids" coordinate system (computer-oriented instrumental pedagogical technologies). According to the researcher, designing a learning environment is a complex process of combining traditional pedagogical technologies and e-learning tools, elements of distance learning, as well as combined and blended learning of students in a virtual environment specially created by a teacher.

The results of the analysis of scientific and methodological literature and periodicals make it possible to assert that the use of webinars helps to solve many problems of the educational process. In particular, researchers $[20,21]$ define the following advantages of webinars:

- $\quad$ minimum costs for events organized and conducted by the university;

- availability for almost an unlimited number of participants;

- interaction between participants and the presenter, which is achieved by means of a chat (most often) or using video communication;

- $\quad$ ability to access web resources during the webinar;

- $\quad$ ability to save the webinar in the appropriate video format.

Despite the obvious advantages of using webinars in organizing the educational process, one should point out several limitations and inconveniences that occur when conducting classes in the form of a webinar [22]:

- almost complete lack of emotional connection, which is an important factor in the discussion process, since the speaker needs to see the emotions of the listeners and react accordingly to maintain attention;

- $\quad$ certain difficulties arise during practical lessons. For example, it is not possible to establish full interaction during practical exercises, since the facilitator does not have the opportunity to independently trace at what stage of the task completion this or that participant is;

- it is difficult, and sometimes completely impossible, to conduct educational work with the participants, since there are no conditions for pedagogical influence on learning and education.

Despite the close attention of the scientific world to issues closely related to distance learning in general and 
conduct of webinars, in particular, some important aspects of this problem remain poorly studied to this day. For example, questions related to the role of multimedia educational technologies (including webinars) in increasing the motivation of teaching students of humanitarian specialties. Meanwhile, these issues are among the main ones due to the existing tendencies towards a decrease in the interest of young people in humanitarian education, as well as in connection with the problems caused by the peculiarities of the perception of educational material in social and psychological disciplines, the assimilation of which has significant specificity.

According to researchers [23,24], motivation is one of the significant elements of education, the level of which directly affects the quality of students' learning activities. Not only the resulting performance indicators of students depend on motivation, but also the degree of their satisfaction with learning, the desire to improve their professional level, subjective comfort, etc. We proceed from the assumption that the introduction, well-known but updated, based on a multimedia complex and presented at a new didactic level means of methodological support of the educational process, makes it possible to predict an increase in the motivation for studying psychological and social disciplines.

In the psychological and pedagogical literature, general approaches to the concept of educational motivation have not yet been developed and there is no general opinion regarding the classification of educational motives. Using the concept of motivation, we proceed from the definition that motivation is a set of motives or arguments for justifying something; motivation [25]. With regard to the educational process, the concept of motivation is concretized and defined as something that encourages students to study a certain subject or discipline and an explanation of the need for learning [26].

Most often, in studies devoted to psychological and pedagogical problems, educational motives are divided into internal and external $[27,28]$. External motives caused by the actions of teachers, university administration, parents, others, as well as society as a whole, take the form of instructions, demands or any other coercion. In the absence of internal motives, they act, but their action often experiences internal resistance from students. Therefore, internal motives cannot be the main ones in the preparation of a future psychologist or social worker. Internal motives of educational activity are the desire to better and deeper master the educational material, an understanding of the need for training for self-realization in the profession, creative satisfaction during the implementation of course projects and independent assignments. Intrinsic motives include the motives for improvement, which are also associated with the process of cognitive actions during the use of the multimedia environment, and the latter, in turn, with the use of webinars. We did not consider other aspects of intrinsic motivation, such as the motivation of prestige, since they cannot be targeted in the study of social and psychological disciplines. Therefore, one of the components of the research goal was to determine the impact of webinars on the relationship between internal and external motives during the educational activities of students of humanitarian specialties.

The purpose of the study is to reveal the influence of webinars as one of the main forms of distance learning of students of social and psychological disciplines on increasing the motivation for learning.

The hypothesis of the study: webinars have a positive effect on students' motivation to acquire knowledge and master a profession.

According to the results of the study, it can be concluded that the purpose set in the study was achieved.

\section{Methods}

The purpose was achieved using the following research methods: theoretical - analysis of psychological, pedagogical and methodological literature on the research problem, analysis of educational literature, educational standards and programs for professional and practical learning of students of humanitarian specialties to generalize theoretical issues of the essence, functions, features of the use of webinars to improve the motivational component of learning; empirical - observation, interviews, questionnaires, as well as analysis of the activities of teachers and students; mathematical-statistical methods of data processing to analyze the impact and trends of changes in student motivation in the case of using webinars.

To identify the educational motives of students of humanitarian specialties, the study used the self-diagnosis method. Students were selected for the study by the method of cluster sampling, according to which students were assigned to the experimental group not individually, but as part of separate clusters - study groups.

In total, 86 students from nine study groups took part in the study, enrolled in full-time courses in the 3rd-4th courses in two humanitarian specialties "psychology" and "social work".

When passing the self-diagnosis test, the well-known methods were used (Methodology for Studying Motivation for Studying at a University by T.I. Iliina and Methodology for Studying Attitudes Towards Academic Subjects by G.N. Kazantseva), which, during the development of the questionnaire, were adapted in accordance with the tasks of the study and met the requirements of reliability, validity and reliability.

To ensure comparability of quantitative assessments of students' motives, which were calculated according to the methods of various authors, scaling was performed and the results were evaluated on a ten-point scale. The test included 65 questions that allowed differentiating measured educational motives on four scales: "internal - 
external motives", "mastering a profession”, “acquiring knowledge and skills", "getting a diploma". Besides the significant questions, the test questionnaire, for masking, included several additional background tasks that were changed randomly and were not processed further. Students' answers to the test questions were analyzed using the mathematical apparatus for processing statistical data.

When summing up the results of self-diagnostics, we took into account students' activity in the classroom, their progress and also the results of the interviews conducted with the students individually.

\section{Results}

Comparative data for the analysis of the effect of webinars on the motives of humanitarian students before and after classes with their use are shown in Table 1.

The use of appropriate self-diagnostic techniques made it possible to assess the accuracy of self-diagnosis, differentiate the motives of students, identify the relationship between internal and external motives and determine the level of motives associated with acquiring knowledge, mastering a profession and getting a diploma.

The accuracy of the applied methodology in relation to each of the measured educational motives was checked by the ratio of the maximum and minimum measurement variances, which turned out to be less than the table value of the Fisher criterion, which indicates the accuracy of the measurement.
Data given in Table 1 confirm the influence of learning using webinars on the motivation of students of humanitarian specialties. By analyzing the data, it should be noted that for all motives there are changes in levels that are measured before and after the webinars. This is evidenced by the increase in such calculated characteristics as mode, median, arithmetic mean (see the ratio B/A) for three groups of motives (acquiring knowledge, mastering a profession, obtaining a diploma).

However, for internal and external motives and the motive for getting a diploma, such changes are statistically insignificant, as evidenced by a comparison of the coefficient of reliability of differences with the tabular values of Student's test.

It also implies that the coefficient of reliability of differences for the motives "acquiring knowledge" and "mastering a profession" is greater than the limiting value of Student's criterion. Therefore, we can conclude that the changes in their levels, determined before and after the webinars, are statistically significant.

Comparison of the quantitative characteristics of the research results (see Table 1) allows us to note the positive impact of webinars on the motivation of students to acquire knowledge and master a profession. For both of these motives, there is an increase in the upward direction of such quantitative characteristics of the distribution of measured values as mode, median and arithmetic mean. The magnitudes of these changes are given in Table 1 as the ratio of the level of the corresponding quantitative characteristic determined after the webinars (B) to the level that was before the webinars $(\mathrm{A})$.

Table 1. Comparative analysis of students' motives when using webinars to assimilate educational material in psychological and social disciplines.

\begin{tabular}{|c|c|c|c|c|c|c|c|c|c|c|c|c|}
\hline & \multicolumn{3}{|c|}{ External/internal } & \multicolumn{3}{|c|}{ Acquiring knowledge } & \multicolumn{3}{|c|}{ Mastering a profession } & \multicolumn{3}{|c|}{ Getting a diploma } \\
\hline & A & B & $\mathrm{B} / \mathrm{A}$ & A & B & $\mathrm{B} / \mathrm{A}$ & A & B & $\mathrm{B} / \mathrm{A}$ & A & B & $\mathrm{B} / \mathrm{A}$ \\
\hline Mo & 16 & 13 & 0.81 & 6 & 9.2 & 1.53 & 3 & 6 & 2 & 6 & 7 & 1.17 \\
\hline $\mathrm{Me}$ & 12 & 13 & 1.08 & 6 & 6.8 & 1.13 & 3.5 & 5 & 1.43 & 6 & 6.5 & 1.08 \\
\hline $\mathrm{a}$ & 11.83 & 12.83 & 1.08 & 5.98 & 6.85 & 1.15 & 4 & 5.14 & 1.29 & 5.51 & 6.16 & 1.12 \\
\hline $\mathrm{D}$ & 18.31 & 22.5 & 1.23 & 5.05 & 4.86 & 0.96 & 5.25 & 4.26 & 0.81 & 6.78 & 5.57 & 0.82 \\
\hline $\mathrm{S}$ & 4.28 & 4.74 & 1.11 & 2.25 & 2.2 & 0.98 & 2.29 & 2.06 & 0.9 & 2.6 & 2.36 & 0.91 \\
\hline $\mathrm{Z}$ & 0.46 & 0.51 & 1.11 & 0.24 & 0.24 & 1 & 0.25 & 0.22 & 0.88 & 0.28 & 0.25 & 0.89 \\
\hline $\mathrm{Kv}$ & 36.18 & 36.98 & 1.02 & 37.58 & 32.19 & 0.86 & 57.27 & 40.17 & 0.7 & 47.23 & 38.29 & 0.81 \\
\hline \multicolumn{13}{|c|}{ Accuracy of experimental techniques } \\
\hline- & \multicolumn{3}{|c|}{ Dmax $/$ Dmin $=1.229<\mathrm{Kf}$} & \multicolumn{3}{|c|}{ Dmax $/$ Dmin $=1.038<\mathrm{Kf}$} & \multicolumn{3}{|c|}{ Dmax $/$ Dmin $=1.231<\mathrm{Kf}$} & \multicolumn{3}{|c|}{ Dmax $/$ Dmin $=1.217<\mathrm{Kf}$} \\
\hline \multicolumn{13}{|c|}{ Reliability of differences } \\
\hline - & \multicolumn{3}{|c|}{ Ko $=1.452<$ Ck not confirmed } & \multicolumn{3}{|c|}{ Ko $=2.562>$ Ck confirmed } & \multicolumn{3}{|c|}{ Ko $=3.427>$ Ck confirmed } & \multicolumn{3}{|c|}{ Ko $=1.719<$ Ck not confirmed } \\
\hline
\end{tabular}

Note: A - before classes using webinars; B - after classes using webinars; Mo - mode; Me -median; a - arithmetic mean; D - variance; S standard deviation; $\mathrm{Z}$ - mean error of the arithmetic mean; $\mathrm{Kv}$ - coefficient of variation,\%; Ko - coefficient of reliability of the difference; Kf = 1.429 and $\mathrm{Ck}=1.974$ - tabular values of Fisher's and Student's tests, respectively (significance level 5\%) 


\section{Discussion}

Speaking about the methodological aspects of conducting webinars for humanities students, it should be noted that the development of webinars in social and psychological disciplines includes the following stages: defining the target group for the webinar, designing the goals of the webinar, analyzing the content of the topic, choosing software and organizational basis for conducting the webinar, selecting the content for a webinar (the main principle is novelty and unusualness), finding problems in mastering this content in full-time and remote form, formulating goals from the perspective of teaching and learning, as well as transforming content into a structured text, defining blocks in a structured text, choosing types of visualization that offer problematic and interactivity of studying a block of structured text, defining the logic of presentation of blocks, forms and methods of their presentation within a webinar, defining a support system for the process of conducting a webinar (showing presentations or videos in which one can increase the "dose" of symbolic information formations, as opposed to face-to-face performance, work with a virtual board, knowledge maps, activity or interactivity of participant polls, organization of a "question-answer" system in the online chat window, etc.).

Webinars do not tie listeners to a specific time frame. For those who cannot be present at the lesson at the time of its holding, a record is available, which can be viewed at any convenient time.

Empirically, researchers [29] have identified the criteria for determining the effectiveness of the methodology for preparing and conducting webinars: level of perception; levels of reproduction of the studied material over a long time and the application of the knowledge gained; increasing the information content and problematic nature of the submitted material; promptness of updating and changing content; levels of student motivation in the process of mastering new things; clarity and accessibility of the platform for the webinar.

Effective teaching methods that arouse the interest of students and intensify their educational and cognitive activity during the webinar are working in pairs, discussion, "brainstorming”, case-method, etc. Internet services, which offer the joint work of a group of participants in real time, help to implement interactive methods in the webinar [30].

Webinars give an opportunity to improve the quality of the educational process and increase student motivation by attracting teachers from other universities in the country and foreign countries. After all, it is considered good form for a university if a lecturer from Harvard, Oxford or a significant specialist or expert is giving a lecture there. As experts say, webinars allow organizing a "global brain transfer” [31]. Moreover, webinars make it possible to involve in teaching and consulting specialists of the highest level without interrupting their main activity, which makes it possible to obtain modern high-quality knowledge for students, young scientists and interested specialists.

\section{Conclusion}

To sum up, the new information and communication technology for conducting webinars is very promising for organizing the educational process and increasing students' learning motivation.

Webinar technology provides powerful functionality for the implementation of distance learning and has significant didactic capabilities. The overwhelming majority of classroom activities of the traditional form can be implemented by means of a webinar. Of course, this form of learning organization cannot completely replace traditional learning, but its use can significantly improve the educational process. The organization of webinars contributes to the growth of the interest of future specialists in obtaining the knowledge necessary for their future professional activities. The methodology for conducting such classes in the form of a webinar has real educational prospects for learning and can be successfully used in the educational process of the university.

A generalization of publications by Russian and foreign authors devoted to the study of ways to motivate students' learning activities, made it possible to establish that, despite the lack of common approaches, in most works, the importance of the problem is confirmed and there is a connection between the effectiveness of learning sessions and students' motivation to learn. Motives for learning are most often divided into internal and external. Both those and others stimulate students to intensify their educational activities; however, during the study of disciplines of a humanitarian orientation, internal motives are of particular interest.

Experimental testing revealed the relationship between students' motivation to study social and psychological disciplines and the use of webinars. It can be noted that the data obtained indicate the effect of webinars on the change in the significance of the motives considered in the study. This is confirmed by the fact that the calculated values of the coefficients of the significance of differences exceed the limit value of Student's test, which was recorded during the determination of the motives "acquiring knowledge" and "mastering a profession" before and after the webinars.

Thus, the hypothesis of the study that webinars have a positive effect on the motivation of students to acquire knowledge and master a profession was confirmed.

\section{Acknowledgments}

The publication was prepared with the support of the “RUDN University Program 5-100”. 


\section{REFERENCES}

[1] I. E. Sokolovskaya, O. B. Polyakova, A. V. Romanova, N. V. Belyakova, K. S. Tereshchuk. Educational and professional motivation of students with various religious orientations, European Journal ofScience and Theology, Vol. 16, No. 4, 169-180, 2020.

[2] M. V. Vinichenko, A. V. Melnichuk, P. Karácsony. Technologies of improving the university efficiency by using artificial intelligence: motivational aspect, Entrepreneurship and Sustainability Issues, Vol. 7, No. 4, 2696-2714, 2020. https://doi.org/10.9770/jesi.2020.7.4(9)

[3] S. V. Arkhipov, E. N. Vanchikova, N. A. Zolotareva, A. E. Yantranov, D. T. Budaeva. Research into Motivational Factors of Work Done by University Teachers from the Perspective of the Theory of Generations, TEM Journal, Vol. 8, No. 4, 1477-1483, 2019.

[4] V. V. Plenkina, I. V. Osinovskaya. Improving the system of labor incentives and stimulation in oil companies, Entrepreneurship and Sustainability Issues, Vol. 6, No. 2, 912-926, 2018. https://doi.org/10.9770/jesi.2018.6.2(29)

[5] T. I. Golubeva, I. I. Kokhanovskaya, E. V. Golovneva, A. L. Fatykhova, N. V. Terekhova. Social networks and education: the increase in student learning efficiency and the search for means of control, Revista Inclusiones, Vol. 7, Special Issue, 48-602, 2020.

[6] N. M. Dugalich, N. V. Alontseva, Yu. A. Vasilieva, I. A. Rubannikova, M. I. Mikheeva, N. V. Kudryashova. Increasing efficiency of foreign-language teaching: gamification technologies in education, Revista Inclusiones, Vol. 7, Special Issue, 151-163, 2020.

[7] V. N. Dolzhenkov, I. D. Maltzagov, A. I. Makarova, N. S. Kamarova, P. V. Kukhtin. Software Tools for Ontology Development. International Journal of Advanced Trends in Computer Science and Engineering, Vol. 9, No. 2, 935-941, 2020 https://doi.org/10.30534/ijatcse/2020/05922020

[8] O. V. Golub, T. S. Timofeeva, M. M. Mansurova. Young people's social representations about childlessness ideology: research with the use of information and communication technologies, Journal of Critical Reviews, Vol. 7, No. 9, 1066-1069, 2020

[9] A.I. Nikiforov, A. M. Avdonina, T. V. Dikova, A. S. Bagdasarian, I. Yu. Ilina. Formation of a Continuing Education System in Modern Conditions, Universal Journal of Educational Research, Vol. 8, No. 5, 1772-1777, 2020. DOI: 10.13189/ujer.2020.080514

[10] S. A. Hrastinski. A theory of online learning as online participation, Computers \& Education, Vol. 52, No. 1, 78-82, 2009.

[11] C. L. Johnson, J. B. Schumacher. Does webinar - based financial education affect knowledge and behavior? Journal of Extension, Vol. 54, 1-10, 2016.

[12] D. Burton, T. Kitchen. Online videoconferencing products: Update, The International Review of Research in Open and Distance Learning, Vol. 12, No. 2, 157-165, 2010.
[13] K. Sura, J. W. Lischalk, J. Leckie, J. S. Welsh, E. Fernandez. Webinar-Based Contouring Education for Residents, Journal of the American College of Radiology, Vol. 14, No. 8, 1074-1079, 2017.

[14] S. Cornelius. Facilitating in a demanding environment: experiences of teaching in virtual classrooms using web conferencing, British Journal of Educational Technology, Vol. 45, 260-271, 2014.

[15] R. Ferguson. Peer interaction: The experience of distance students at a university level, Journal of Computer Assisted Learning, Vol. 26, 574-584, 2010.

[16] K. Kear, F. Chetwynd, J. Williams, H. Donelan. Web conferencing for synchronous online tutorials: perspectives of tutors using a new medium, Computers \& Education, Vol. 58, 953-963, 2012.

[17] A. Gegenfurtner, A. Zitt, C. Ebner. Evaluating webinar-based training: a mixed methods study of trainee reactions toward digital web conferencing, International Journal of Training and Development, Vol. 24, No. 1, 5-21, 2019.

[18] W. P. McKinney. Assessing the evidence for the educational efficacy of webinars and related internet - based instruction, Pedagogy in Health Promotion: The Scholarship of Teaching and Learning, Vol. 3, 475-515, 2017.

[19] R. Polanco-Bueno. Blogs, webinars and significant learning: a case report on a teacher training program for college teachers, Higher Learning Research Communications, Vol. 3, 56-67, 2013.

[20] S. - K. Wang, H. - Y. Hsu. Use of the webinar tool (Elluminate) to support training: the effects of webinar learning implementation from student - trainers 'perspective, Journal of Interactive Online Learning, Vol. 7, 175-194, 2008.

[21] M. Ward, G. Peters, K. Shelley. Student and faculty perceptions of the quality of online learning experiences, The International Review of Research in Open and Distance Learning, Vol. 11, No. 3, 57-77, 2010.

[22] C. C. Pan, M. Sullivan. Promoting synchronous interaction in an eLearning environment, THE Journal, Vol. 33, No. 2, 27-30, 2005.

[23] N. A. Bakshaeva, A.A. Verbitskii. Psikhologiia motivatsii studentov [Psychology of Student Motivation], Academiia, Moscow, 2006, 325 p. (in Russian).

[24] R. I. Tsvetkova. Motivatsionnaia sfera lichnosti studenta kak subektivno-razvivaiushchaiasia sistema [The Motivational Sphere of the Student's Personality as a Subjectively Developing System], Grif UMO, Khabarovsk, 2006, 192 p. (in Russian).

[25] V. G. Leontiev. Psikhologicheskie mekhanizmy motivatsii uchebnoi deiatelnosti: Ucheb. posobie [Psychological Mechanisms of mMotivation for Learning Activity: a Study Guide], NGPI, Novosibirsk, 1987, 89 p. (in Russian).

[26] T. S. Tikhomirova, N. V. Kochetkov. Learning motivation and personal reflection in students: features and relationship, Psikhologicheskaya nauka i obrazovanie $=$ Psychological Science and Education, Vol. 22, No. 3, 53-62, 2017. DOI:10.17759/pse.2017220306 (in Russian, abstr. in English). 
[27] A. A. Rean, N. V. Bordovskaia, S. I. Rozum. Psikhologiia i pedagogika [Psychology and Pedagogy], Piter, Saint-Petersburg, 2005, 432 p. (in Russian).

[28] I. A. Zimniaia. Pedagogicheskaia psikhologiia: uchebnik dlia vuzov. 2-e izd. dop., ispr. i pererab. [Educational Psychology: Textbook for Universities. $2^{\text {nd }}$ Edition. Added and Revised], Logos, Moscow, 2005, 382 p. (in Russian).

[29] V. Zomenou, M. Sigman-Grant, G. Coleman, F. Malekian, J. M. K. Zee, B. J. Fountain, A. Marsh. Identifying best practices for an interactive webinar, Journal of Family \&
Consumer Services, Vol. 107, 62-69, 2015.

[30] Q. Wang, H. L. Woo. Comparing asynchronous online discussions and face-to-face discussions in a classroom setting, British Journal of Educational Technology, Vol. 38, No. 2, 272-286, 2007.

[31] A. Gegenfurtner, D. Festner, W. Gallenberger, E. Lehtinen, H. Gruber. Predicting autonomous and controlled motivation to transfer training, International Journal of Training and Development, Vol. 13, No. 2, 124-138, 2009. 